\title{
APRENDIZAGEM SOCIAL PARA SUSTENTABILIDADE: A EXPERIÊNCIA DE UM PROGRAMA EMPRESARIAL DE MULHERES EMPREENDEDORAS EM SITUAÇÃO DE POBREZA
}

Diego Gama Amaral

Mestre em Administração de Empresas

Universidade Presbiteriana Mackenzie São Paulo - São Paulo - Brasil

Janette Brunstein

Doutora em Educação

Universidade Presbiteriana Mackenzie

São Paulo - São Paulo - Brasil

\section{RESUMO}

O propósito desse estudo é expandir as discussões da literatura de Aprendizagem Social para Sustentabilidade, direcionada à temática de problemas ambientais, ao analisar o processo de aprendizagem social à luz da sustentabilidade social, em um projeto de combate à pobreza. Trata-se de um estudo de caso em uma rede de empreendimentos pertencente ao Programa Mulher Empreendedora do Instituto Consulado da Mulher, a principal ação social da marca Consul. A observação não participante foi a principal técnica de coleta de dados, complementada por análises documentais e entrevistas semiestruturadas. Como resultados, três fatores-chave são responsáveis por estimular a aprendizagem social entre as participantes: (a) a possibilidade de troca de experiências, devido ao formato da rede de empreendimentos; (b) o estímulo à qualidade de um diálogo mais aberto e democrático; (c) a necessidade de um mediador, encarregado pelo processo de facilitação das discussões e reflexões. Os fatores-chave criaram condições para a existência de cinco elementos críticos que influenciaram, em maior ou menor grau, o nível de aprendizagem social: (1) reflexão e pensamento crítico; (2) negociação e colaboração; (3) barreiras ao processo de aprendizagem; (4) participação e engajamento; (5) comunicação. Tais resultados também trazem implicações práticas para gestores que desejam criar projetos similares, especialmente em relação à construção de processos de mediação dos diálogos, via a figura do educador social.

Palavras-chave: Aprendizagem organizacional; Aprendizagem social; Empreendedorismo popular; Sustentabilidade.

\section{SOCIAL LEARNING FOR SUSTAINABILITY: THE EXPERIENCE OF A BUSINESS PROGRAM FOR WOMEN ENTREPRENEURS IN POVERTY SITUATION}

\begin{abstract}
The purpose of this study is to expand the discussions on the Social Learning for Sustainability literature, focused on environmental issues, through the analysis of the social learning process under the social sustainability perspective, in a project to poverty alleviation. This is a case study in a network of entrepreneurs belonging to the Programa Mulher Empreendedora do Instituto Consulado da Mulher (ICM), the main social action of the brand Consul. Non-participant observation was the primary technique of data collection, complemented by documentary analyzes and semi-structured interviews. As results, we found that three key factors are responsible for stimulating social learning among participants: (a) the possibility of exchanging experiences, due to the format of the entrepreneurship network; (b) encouraging the quality of a more open and democratic dialogue; (c) the need of a mediator, responsible for the process of facilitating discussions and reflections. The key factors created conditions for the existence of five critical elements that influenced, to a greater or lesser extent, the level of social learning: (1) reflection and critical thinking; (2) negotiation and collaboration; (3) barriers to the learning process; (4) participation and engagement; and (5) communication. These results also have practical implications for managers who wish to create similar projects, especially concerning to the construction of mediation processes of dialogues via the social educator.
\end{abstract}

Key words: Organizational learning; Popular entrepreneurship; Social learning; Sustainability. 


\section{INTRODUÇÃO}

A interação entre os sistemas ambientais, sociais e econômicos faz parte de um processo social, resultante de mudanças na interação entre atores sociais e as estruturas das quais estão vinculados (Rist, Chidambaranathan, Escobar, Wiesmann \& Zimmermann, 2007). Nesse contexto, surge a aprendizagem social como facilitadora do processo de transição para uma sociedade mais sustentável. Por seu caráter colaborativo, mostra-se como uma prática relevante na construção de uma cultura de diálogo e participação entre os atores (Jacobi, 2008), uma vez que é pensada para aumentar a flexibilidade e a capacidade de resposta dos sistemas socioambientais, permitindo que a relação homem-ambiente possa melhor se adaptar ao estresse e às mudanças, sem alterar a sua natureza essencial (Fernandez-Gimenez, Ballard \& Sturtevant, 2008). A esse fenômeno denomina-se Aprendizagem Social para Sustentabilidade (ASpS).

Há diferentes formas de configuração de aprendizagem social (Wals \& Rodela, 2014). Há casos em que é necessário dar uma ênfase maior às ferramentas e aos métodos para atingir um objetivo pré-definido, em outros, é preciso estimular resultados mais subjetivos. No entanto, essa reflexão da literatura de ASpS se concentra nas discussões sobre recursos naturais, mais precisamente na gestão hídrica, e a necessidade de envolver múltiplos atores em busca de objetivos comuns (Maarleveld \& Dangbégnon, 1999; Pahl-Wostl, Sendzimir, Jeffrey, Aertis, Berkamp \& Cross, 2007). É preciso, portanto, estender o debate da aprendizagem social à dimensão social, que abrange desde o acesso aos recursos básicos tangíveis - água, comida, medicamentos e habitação - até às necessidades menos tangíveis em matéria de educação, emprego, equidade e justiça social (Vallance, Perkins \& Dixon, 2011). Tais demandas, aliadas à incapacidade do indivíduo de exercer direitos, poder e participação na sociedade, refletem o conceito de pobreza.

Nesse sentido, esse estudo busca responder a seguinte pergunta de pesquisa: Como ocorre o processo de aprendizagem social em uma rede de empreendimentos populares voltada para o desenvolvimento social?

Este trabalho pretende trazer, como contribuição à literatura de ASpS, a discussão sobre o processo de aprendizagem social à luz da sustentabilidade social, estudado com base em um projeto de combate à pobreza. Para sustentar este debate, foi realizado em estudo de caso em uma rede de empreendimentos populares geridos por mulheres de baixa renda do Programa Mulher Empreendedora, vinculado ao Instituto Consulado da Mulher (ICM), principal ação social da empresa Consul. O caso escolhido permite endereçar discussões para projetos de combate à pobreza ao trazer novos argumentos para a literatura de ASpS, por meio de três fatores-chave que explicam os resultados positivos do projeto em estimular a aprendizagem social dos envolvidos: (a) a possibilidade de troca de experiências, incentivada pelo formato da rede de empreendimentos; (b) o estímulo à qualidade de um diálogo mais aberto e democrático; e (c) a necessidade de um mediador, o Educador Social, encarregado pelo processo de facilitação das discussões e reflexões.

Uma vez que o objeto de estudo é uma rede de empreendimentos, é preciso também abordar a aprendizagem social no âmbito organizacional, originada da prática da vida diária, na qual organização e indivíduos são constituídos de forma sistêmica, por meio de interações (Elkjaer, 2004). Os estudos que compartilham essa visão corroboram em três pontos (Elkjaer, 2004; Gherardi \& Nicolini, 2001; Shipton \& DeFillippi, 2003): (i) A aprendizagem organizacional é mediada por processos cognitivos de interpretação e construção de sentido; (ii) O saber é a capacidade de participar na complexa teia de relacionamentos entre indivíduos, artefatos e atividades; e (iii) As pessoas não assumem papeis prontos, mas os criam e recriam de acordo com determinada situação.

Em se tratando de aprendizagem social orientada para sustentabilidade no ambiente organizacional, reforça-se a importância das interações sociais e seus diálogos, dos questionamentos frente aos problemas encontrados, da necessidade de mudança e da experiência obtida continuamente por meio da vivência diária. Para se observar isso na prática, é importante discutir o conceito da aprendizagem social organizacional considerando metas de sustentabilidade. Nesse sentido, esse artigo se propõe também a fazer tal integração. Tratadas separadamente, essas perspectivas são amplamente estudadas (aprendizagem social organizacional e sustentabilidade), mas carecem de uma aproximação. Quanto às implicações práticas, procura-se fornecer subsídios para alavancar projetos que visam o desenvolvimento social, no caso a pobreza, a partir de um conhecimento mais claro sobre processo de aprendizagem entre os atores envolvidos.

\section{FUNDAMENTAÇÃO TEÓRICA}

O referencial teórico inicia com uma discussão sobre o conceito de Aprendizagem Social para Sustentabilidade (ASpS) para, em seguida, conectá-lo aos estudos de aprendizagem organizacional. 


\subsection{Aprendizagem social para sustentabilidade}

A sustentabilidade não é um objetivo final estático, mas um processo de contínuo aprendizado em busca de um estado desejado (Wals \& Rodela, 2014). Para tanto, é preciso confrontar modelos mentais e políticas vigentes, buscando mudanças estruturais e institucionais ao invés de abordagens superficiais. Por essa razão, a sustentabilidade requer aprendizagem social em grande escala para estimular pessoas a desafiarem práticas existentes (Jacobi, 2008; Loeber, Mierlo, Grin \& Leeuwis, 2007; Tilbury, 2007) e é desencadeada tanto por uma necessidade em particular quanto por um conjunto de competências que estão presentes no sistema social envolvido (Wildemeersh, 2007).

Henry (2009) comenta sobre a importância da ASpS a partir de dois problemas-chave. Em primeiro lugar, a sustentabilidade possui definições distintas para atores diferentes, requerendo a aprendizagem de objetivos comuns e estratégias adequadas para benefícios de todos os envolvidos. Em segundo lugar, os problemas de sustentabilidade normalmente surgem das interações complexas entre os sistemas sociais e ecológicos, e não há informações suficientes para entender como esses sistemas vão reagir a qualquer alternativa de ação tomada. Esta informação deve ser aprendida de alguma forma.

A comunicação, cooperação, ação e reflexão são elementos essenciais da aprendizagem social para promover o desenvolvimento sustentável (Dlouhá, Barton, Janousjová \& Dlouhý, 2013). Com este olhar, Keen, Brown e Dyball (2005) definem a ASpS como um processo interativo de reflexão que ocorre quando compartilhamos as experiências, ideias e o meio ambiente, envolvidos por um clima de colaboração entre os diversos participantes. Este conceito enfatiza o aprendizado por meio de interações em um ambiente de grupo, incorporado em um contexto sociocultural, e a natureza da aprendizagem como um ato consciente de autorreflexão coletiva. Ainda assim, para Garmendia e Stagl (2010), a profundidade do aprendizado depende do processo de mediação entre os envolvidos, o tempo destinado para tanto e as características dos participantes.

O processo de reflexão per si não pode ser considerado como aprendizagem, pelo contrário, precisa apresentar mudanças em diferentes níveis desencadeadas pelas interações sociais. Reed, Evely, Cundill et al. (2010) apontam três elementos que corroboram para a incidência da aprendizagem social: (i) contemplar a mudança no entendimento dos indivíduos envolvidos, seja em níveis superficiais, por meio de novas informações, ou mais profundos, demonstrados pela mudança de atitudes, visões de mundo e crenças epistemológicas; (ii) sobrepujar o âmbito individual das mudanças para se tornarem contextualizadas em unidades sociais mais amplas; e (iii) acontecer por intermédio de relações sociais e processos entre múltiplos atores dentro de uma rede social.

A dimensão humana tem sido negligenciada nos estudos de ASpS, concentradas massivamente em temas ambientais, mesmo havendo ligações entre a pobreza, desigualdade e degradação ambiental (Hahn, 2009; Lélé, 1991). Os autores que discutem o conceito de sustentabilidade social comentam o quão difícil é criar uma definição única, haja vista o seu caráter abrangente. Por esse motivo, os estudos sobre o tema buscam encontrar elementos comuns da sustentabilidade social.

Boström (2012), por exemplo, indica como um dos objetivos da sustentabilidade social a segurança econômica das pessoas, por meio de acesso a comida e moradia. Vifell e Soneryd (2012) se referem ao empoderamento de grupos sociais mais fracos. Dempsey, Bamley, Power e Brown (2011) atribuem à sustentabilidade social no ambiente urbano como a inexistência de práticas discriminatórias quanto à participação econômica, social e política na sociedade. Finalmente, Eizenberg e Jabareen (2017) comentam que quanto maior a equidade e justiça social, menor a probabilidade de reduzir a alienação de pessoas sobre o seu espaço, o que aumenta a sua preocupação com questões ambientais.

A assistência à micro e pequenos empreendimentos têm sido uma das saídas para aumento da receita, produtividade e ativos dos mais carentes (Tinker, 2000). Os programas de redução de pobreza com tais características mostraram ser mais efetivos do que aqueles que prezam apenas pelo assistencialismo. Adicionalmente, a autora ratifica que o foco nas oportunidades empresariais em mulheres tem provado ser mais efetivo em prover comida e carinho para as crianças do que aquelas voltadas aos homens. A importância de estudar empreendimentos geridos por mulheres de baixa renda como uma das saídas para combate à pobreza justifica a abordagem da aprendizagem social no ambiente organizacional.

Tendo em vista que o objetivo é transpor o conceito da Aprendizagem Social para Sustentabilidade, para uma análise mais micro, a do ambiente organizacional, trata-se de pensar como estabelecer tal articulação. É sobre isso que trata o tópico seguinte. 


\subsection{Aprendizagem social nas organizações}

A literatura de aprendizagem organizacional é composta por duas metáforas: "aquisição de conhecimento" e "participação" (Elkjaer, 2004). Na primeira, a aprendizagem acontece no nível individual (âmbito cognitivo), para depois ser formalizada em rotinas da organização. Na segunda metáfora, o foco não é no indivíduo, mas em processos coletivos.

A aprendizagem social nas organizações, a terceira via proposta por Ekjaer (2004), é definida como o desenvolvimento da experiência e conhecimento por meio de questionamentos (ou pensamentos reflexivos) em mundos sociais unidos por compromisso. Essa perspectiva tenta complementar críticas relacionadas às outras metáforas: se na aquisição encontra-se dificuldade na explicação da transferência de conhecimento do indivíduo à organização; na metáfora da participação, há problemas em esclarecer como acontece o aprendizado em um determinado contexto. Nesse sentido, o entendimento da aprendizagem organizacional fundamenta-se a partir da conexão entre os processos individuais, o funcionamento dos grupos e as relações sociais, abrangendo os conceitos das duas outras metáforas.

O indivíduo é considerado como a entidade base da aprendizagem. As capacidades cognitivas individuais e o contexto social determinam a aprendizagem, por isso a importância da interação recíproca entre indivíduo e o contexto, necessária às mudanças. Em outras palavras, quando os indivíduos são incapazes de influenciar o contexto por meio do seu comportamento, todo o sentido de tradução de conhecimento em ação desaparece. Se o contexto é inapto em mudar o indivíduo, verifica-se a continuidade de práticas antigas.

A aprendizagem se dá na experiência diária, construída com base em fatos vivenciados, em um processo contínuo de acontecimentos no qual há uma objetividade no compartilhamento social que se entrelaça com a dimensão subjetiva individual (Elkjaer \& Simpson, 2006). Refere-se a pensamentos que tomam como base vivências passadas para influenciar e antecipar expectativas futuras. Em outras palavras, a experiência vai muito além de conhecimento, trata-se de fatos vividos da natureza transacional e social.

A participação possibilita a criação de significados. Novas ideias são construídas com base em um processo contínuo de acontecimentos, ao invés de originar-se de uma visão particular sobre a natureza de uma realidade pré-existente. A noção de eu social como um ser está continuamente em formação, um devir (Elkjaer \& Simpson, 2006). Os gatilhos que motivam a aprendizagem são de natureza interna e externa, ambas responsáveis pela mudança de atitudes dos indivíduos. Enquanto Dewey concentra-se no âmbito interno, ou seja, no conceito de questionamento ("Inquiry", em inglês), Strauss (1993) utiliza as concepções de mundos e arenas sociais como compreensão de fatores externos que estimulam a aprendizagem.

"Pensar é um processo de questionamento, de olhar para as coisas, de investigar. Adquirir é sempre secundário e instrumental para o ato de questionar. Ele está buscando algo que não está na mão" Dewey (1916 [1980], como citado em Elkjaer, 2004, p. 425). O questionamento acontece quando algo está errado e os resultados finais estão aquém das expectativas. Durante esse processo, o indivíduo sonda se a decisão acatada será aceita socialmente (Elkjaer \& Simpson, 2006). Portanto, a experiência é adquirida e a semente do conhecimento é plantada quando se envolve reflexão, iniciada a partir do momento em que se usa o pensamento como instrumento para tentar resolver uma situação incerta (Brandi \& Elkjaer, 2006).

Os esforços para dar sentido à atividade em andamento envolvem hábitos como um recurso de experiência baseado em categorias de atos que se tornam, graças à repetição e familiaridade cultural, gestos significativos que medeiam uma ação situada (Lorino, 2013). Assim, o questionamento termina quando os atores envolvidos concordam que foram definidos novos hábitos viáveis, tornando possível a continuação da experiência. A aprendizagem organizacional, portanto, é entendida como um processo que transforma uma situação organizacional incerta em uma situação mais estável (Brandi \& Elkjaer, 2013).

As organizações são vistas como arenas de ações coletivas coordenadas, resultantes de comprometimento com as atividades organizacionais (Strauss, 1993). Isto significa que os conflitos organizacionais e tensões derivam de diferentes compromissos a diferentes ações, atividades e valores. Por essa razão, argumenta-se que as tensões podem criar caminhos para questionar as práticas existentes e para o pensamento crítico e a reflexão (Brandi \& Elkjaer, 2006). Assim, provê a imagem da organização como processos de negociações de diferentes vozes ou mundos sociais (Huysman \& Elkjaer, 2006) que dividem recursos e compartilham ideologias para alcance dos objetivos (Elkjaer, 2004).

Em teoria, é possível relacionar os conceitos apresentados por Elkjaer como facilitadores do processo de aprendizagem organizacional, aos fatores que dificultam a aprendizagem no nível de grupos abordados por Edmondson $(1999 ; 2002)$. A perspectiva de Elkjaer baseia-se no entendimento de que a aprendizagem organizacional surge da conexão entre os processos individuais, o funcionamento dos grupos e

Revista de Gestão Social e Ambiental - RGSA, São Paulo, v. 11, n. 3, p. 02-20, set./dez. 2017. 
as relações sociais. Nessa mesma linha, Edmondson define a aprendizagem organizacional como um processo, por meio do qual reconhece a mudança como papel significativo. A organização aprende quando suas ações são modificadas como resultado da reflexão.

A aprendizagem no nível do grupo é difundida por intermédio do comportamento de aprendizagem, isto é, quando os membros da equipe testam hipóteses e discutem as diferenças de opinião de maneira aberta, ao invés de individualmente ou fora do grupo. Assim, para a autora, as barreiras de aprendizagem influenciam negativamente a passagem reflexão-ação, sendo, em especial, duas delas relacionadas ao propósito deste artigo.

A primeira refere-se à influência do poder no processo de reflexão-ação. Se, por um lado, a reflexão significa o compartilhamento de informações no grupo e um ambiente propício para experimentar, por outro, a ação envolve a concretização dos planos. No entanto, quando as diferenças de poder entre os membros do grupo criam percepções de riscos interpessoais, o processo de aprendizagem dá lugar às necessidades de autoproteção. A segunda barreira, as interações frágeis entre os membros do grupo, surge quando o agir decorre do fato ocorrido e não do planejamento de possíveis eventos. Em um ambiente de pouca possibilidade de reflexão, os membros não se escutam, causando desentendimentos em razão de conhecimentos mútuos limitados.

A integração da aprendizagem social entre as esferas da sustentabilidade e da organização está representada na tabela 1 . Há elementos comuns que aproximam as duas abordagens. A aprendizagem se dá por meio de interações sociais em um determinado contexto (quem aprende?). O aprendizado é responsável por mudanças de caráter superficial (práticas), ou por níveis mais profundos de transformação, como a reavaliação de pressupostos e valores (o que aprende?). O papel da experiência e participação no dia-a-dia para o aprendizado (como aprende?). Finalmente, a importância dos questionamentos frente à situação atual (por que aprende?).

Tabela 1.

Quadro analítico da aprendizagem social

\begin{tabular}{|l|l|l|}
\hline \multicolumn{1}{|c|}{ Questões } & \multicolumn{2}{|c|}{ Dimensões da aprendizagem social } \\
\cline { 2 - 3 } Quem aprende? & $\begin{array}{l}\text { Sustentabilidade } \\
\text { Diferentes atores participantes de um } \\
\text { projeto específico. }\end{array}$ & \multicolumn{1}{c|}{ Organizacional } \\
\hline O que aprende? & $\begin{array}{l}\text { Ciclos de aprendizagem dos atores } \\
\text { influenciam o nível de mudança de } \\
\text { práticas, pressupostos e valores correntes } \\
\text { em um determinado projeto. }\end{array}$ & $\begin{array}{l}\text { Os ciclos de aprendizagem, ou a } \\
\text { transformação em hábitos, impactam } \\
\text { diretamente nas rotinas, nos pressupostos e } \\
\text { valores da organização. }\end{array}$ \\
\hline Como aprende? & $\begin{array}{l}\text { O estímulo à colaboração promove a } \\
\text { diversidade na participação de atores que } \\
\text { trazem à tona diferentes considerações. }\end{array}$ & $\begin{array}{l}\text { Experiência diária e participação como uma } \\
\text { forma de criação de significados. }\end{array}$ \\
\hline Por que aprende? & $\begin{array}{l}\text { Aprendizagem social fortalecida por } \\
\text { interesses contraditórios pode envolver } \\
\text { momentos de crises, importantes para o } \\
\text { processo de reflexão-ação. }\end{array}$ & $\begin{array}{l}\text { Questionamentos e reflexões das práticas } \\
\text { vigentes em consequência de problemas } \\
\text { identificados por resultados aquém do } \\
\text { esperado. } \\
\text { Mundos e arenas sociais como conceitos } \\
\text { relacionados ao comprometimento dos } \\
\text { indivíduos e à importância dos conflitos na } \\
\text { busca de soluções para os problemas. }\end{array}$ \\
\hline
\end{tabular}

Nota. Tabela elaborada pelos autores.

\section{MÉTODO DE PESQUISA}

Essa seção subdivide-se em dois tópicos. O primeiro deles, apresenta o caso e a sua importância na relação entre os temas de aprendizagem e desenvolvimento social. $\mathrm{O}$ segundo, aborda o procedimento metodológico do estudo, leia-se, a estratégia de pesquisa e a forma como os dados foram coletados e analisados.

\subsection{Visão geral do ICM e do Programa Mulher Empreendedora}

O objeto de estudo escolhido é o Programa Mulher Empreendedora do Instituto Consulado da Mulher (ICM), principal ação social da Consul, marca pertencente à Whirlpool Latin America. O Consulado desenvolve e consolida programas e práticas sociais voltados ao empoderamento econômico de mulheres, 
com a estratégia de ampliar as habilidades desse público e acompanhar os empreendimentos populares, do seu nascimento à expansão. A missão do ICM é assessorar os empreendimentos populares protagonizados por mulheres, com aporte de conhecimentos e recursos que viabilizem a geração de renda e a qualidade de vida.

As mulheres passam a conhecer o Programa por meio de reuniões na comunidade, muitas vezes na própria associação de bairro. Nessas ocasiões, profissionais do ICM explicam o funcionamento do projeto para, a partir daí, ou iniciar um movimento de criação de um novo empreendimento com as interessadas, ou integrá-las às outras mulheres que já atuam nos negócios existentes.

Os empreendimentos são acompanhados pelas equipes de Educadores Sociais que participam de todas as etapas de desenvolvimento dos negócios durante o processo chamado de assessoria, desde os treinamentos técnicos sobre limpeza de produtos, estoque, disposição de materiais da cozinha, por exemplo, até mediações nos processos de discussões entre as mulheres. Trata-se de um profissional que auxilia as participantes no questionamento das práticas vigentes, assim como no processo de reflexão na busca de soluções. Em todo caso, são vistos pelas empreendedoras não como uma pessoa que responde às dúvidas, mas que as fazem pensar, incentivando-as, inclusive, a resolver os problemas dentro do próprio grupo.

Algumas estratégias auxiliam o desenvolvimento dos negócios, como o agrupamento de empreendimentos segundo suas demandas e necessidades comuns por intermédio do incentivo ao fortalecimento da atuação em rede, como a "União de Sabores Solidários" (USS). Fundada em 2012, a rede conta com a participação de 11 empreendimentos, distribuídos na baixada santista, ABC paulista e Grande São Paulo, beneficiando mais de 70 empreendedoras populares.

Os empreendimentos participantes são devidamente formalizados como pessoa jurídica. A condução de cada negócio é realizada pelo respectivo grupo de mulheres que assume a posição de sócias. Essa configuração estimula a colaboração mútua nas atividades cotidianas, o que pôde ser constatado nas observações de campo e nas entrevistas. O lucro é dividido pela quantidade de horas trabalhadas por cada membro. Na USS, os empreendimentos são divididos entre produtores e vendedores. Os primeiros fornecem produtos aos segundos, possuindo liberdade de suprir outros negócios fora da rede, inclusive com serviço de Buffet para eventos. Os vendedores, por sua vez, compram dos fornecedores da rede, mas também há ocasiões em que produzem, quando possível.

Os representantes dos empreendimentos se encontram semanalmente nas chamadas reuniões de rede, para discutir sobre problemas e andamento das atividades. Trata-se de um processo contínuo importante para reflexão das empreendedoras, uma vez que acontece no horário comercial, mas com a porta do negócio fechada, sem a correria da operação. As reuniões são divididas tendo em vista as quatro localidades que, neste estudo, são denominadas de redes: a rede da Anchieta (SP), a da Berrini (SP), Mauá e São Bernardo do Campo.

O estudo de caso é a estratégia metodológica de pesquisa utilizada para compreender o fenômeno da aprendizagem social na rede de empreendimentos populares do Programa Mulher Empreendedora. Os dados foram obtidos de três fontes: documentos oficiais cedidos pelo ICM, observação não participante, e entrevistas. As observações foram o pilar central da coleta de dados. Ao presenciar as reuniões da rede de empreendimentos, foi possível entender detalhadamente o seu funcionamento, as interações entre os participantes, os problemas enfrentados por cada empreendimento e as reflexões oriundas dos processos de questionamentos.

Ao todo, foram 35 horas de observação durante seis meses de acompanhamentos semanais. De forma a dar um caráter mais formal e objetivo às observações, os pesquisadores elaboraram um roteiro prévio, tendo como referencial teórico a aprendizagem social (tabela 2), de modo a facilitar a qualificação dos comportamentos das empreendedoras e as anotações de campo. 
Tabela 2.

Roteiro das observações

Fenômenos observados

Percepção das empreendedoras quanto à existência de um problema (evento inesperado) e a sua resposta a ele (resolução e adaptação).

Preocupação das empreendedoras em pensar o problema e a sua solução.

Formas de participação/engajamento e a sua influência nas interações (nível de hierarquia, sinergia no trabalho e etc.).

Relação de poder e negociação nas interações: quem possui mais (ou menos) voz nas discussões e o porquê.

Características dos diálogos: se realizados abertamente, sem hierarquia e com a possibilidade de participação igualitária dos envolvidos; ou de maneira hierárquica em um estilo de comando e controle.

Identificação de barreiras e facilitadores nas interações entre as empreendedoras.

Nota. Tabela elaborada pelos autores

As entrevistas serviram de apoio aos dados coletados nas observações como forma de corroborar, ou complementar, as evidências até então descobertas. Para tanto, houve o cuidado de serem realizadas após a primeira observação em campo, possibilitando inserir elementos contextuais nas conversas. Foram seis entrevistas com mulheres empreendedoras que participam do Programa, nomeadas como E1, E2, E3, E4, E5 e E6.

A construção dos dados e as suas respectivas análises foram inspiradas em Flores (1994). Os fragmentos textuais identificados como relevantes para a pesquisa, resultantes das transcrições das entrevistas e das notas de observação, foram reunidos em grupos de unidades de conteúdo semelhantes, em um procedimento de segmentação e atribuição de códigos aos fragmentos discursivos que, por sua vez, constituíram 13 categorias (Tabela 3). Estas foram definidas com acuidade, de forma a atender as dimensões exploradas no referencial teórico.

Tabela 3.

Códigos e suas categorias

\begin{tabular}{|c|c|}
\hline Código & Definição da categoria \\
\hline QUE & Os questionamentos surgem quando algo está errado e os resultados estão aquém das expectativas. \\
\hline EXP & O indivíduo aprende na experiência diária, por meio de fatos vivenciados por ele. \\
\hline HAB & $\begin{array}{l}\text { Hábitos como um recurso de experiência baseado em categorias de atos que se tornam, na repetição e } \\
\text { familiaridade cultural, algo reconhecível e previsível. }\end{array}$ \\
\hline MUD & $\begin{array}{l}\text { A aprendizagem ocorre mediante mudanças oriundas da interação recíproca entre indivíduo e } \\
\text { contexto. }\end{array}$ \\
\hline PAR & $\begin{array}{l}\text { A participação de diferentes atores como uma forma de partilhar responsabilidades e compartilhar } \\
\text { aprendizagem sobre diversas questões. }\end{array}$ \\
\hline $\mathrm{COM}$ & Mundos sociais emergem como resultado do compromisso com as atividades organizacionais. \\
\hline TEN & $\begin{array}{l}\text { Situações de conflitos e tensões entre os mundos sociais podem criar caminhos para questionar as } \\
\text { práticas existentes e estimular o pensamento crítico e a reflexão. }\end{array}$ \\
\hline FUT & $\begin{array}{l}\text { A visão de futuro ideal ajuda a contextualizar as ambições individuais e tenta resolver as diferenças de } \\
\text { expectativas dos envolvidos. }\end{array}$ \\
\hline DIA & $\begin{array}{l}\text { Os diálogos entre os participantes contribuem para a resolução de conflitos e as discussões de ideias e } \\
\text { soluções adequadas. }\end{array}$ \\
\hline LIN & $\begin{array}{l}\text { Linguagem comum, transparente, tolerante, colaborativa e movida a interesses mútuos como } \\
\text { características essenciais de um diálogo que estimula a aprendizagem entre os participantes. }\end{array}$ \\
\hline DEM & $\begin{array}{l}\text { A possibilidade de questionar qualquer proposta democraticamente, expressando alguma ideia nova, } \\
\text { necessidade ou desejo, e a garantia de que haja uma distribuição simétrica de oportunidades e } \\
\text { capacidades de expressão entre os participantes. }\end{array}$ \\
\hline POD & $\begin{array}{l}\text { As diferenças de poder entre os membros do grupo criam percepções de riscos interpessoais. Nesses } \\
\text { casos, o processo de aprendizagem dá lugar às necessidades de autoproteção. }\end{array}$ \\
\hline INT & $\begin{array}{l}\text { Nas interações frágeis entre os membros do grupo, o agir decorre do fato ocorrido e não do } \\
\text { planejamento de possíveis eventos. Os indivíduos não se escutam. }\end{array}$ \\
\hline
\end{tabular}

Nota. Tabela elaborada pelos autores

No passo seguinte, as categorias foram interligadas de acordo com a semelhança temática. A esse conjunto de categorias afins denomina-se metacategoria (Flores, 2004), compostas, neste estudo, por cinco distintas (Tabela 4), embasadas pelo referencial teórico.

Revista de Gestão Social e Ambiental - RGSA, São Paulo, v. 11, n. 3, p. 02-20, set./dez. 2017. 
Tabela 4.

Metacategorias e suas definições

\begin{tabular}{|l|l|}
\hline Nome & Definição da metacategoria \\
\hline $\begin{array}{l}\text { Reflexão e } \\
\text { pensamento crítico }\end{array}$ & A reflexão surge quando os atores se deparam com um problema ou situação incerta. \\
\hline $\begin{array}{l}\text { Negociação e } \\
\text { colaboração }\end{array}$ & $\begin{array}{l}\text { A colaboração a partir do compromisso individual dos atores, visão de futuro e } \\
\text { superação dos conflitos e tensões. }\end{array}$ \\
\hline $\begin{array}{l}\text { Barreiras ao processo } \\
\text { de aprendizagem }\end{array}$ & $\begin{array}{l}\text { Os obstáculos à aprendizagem derivados da centralização de determinados atores e das } \\
\text { interações frágeis entre os membros do grupo. }\end{array}$ \\
\hline $\begin{array}{l}\text { Participação e } \\
\text { engajamento }\end{array}$ & $\begin{array}{l}\text { O papel da participação dos atores e as mudanças de comportamentos por meio das } \\
\text { interações entre indivíduos e contexto social. }\end{array}$ \\
\hline Comunicação & $\begin{array}{l}\text { A importância do diálogo claro, transparente e democrático para o processo de } \\
\text { aprendizagem. }\end{array}$ \\
\hline
\end{tabular}

Nota. Tabela elaborada pelos autores.

Por fim, o agrupamento das categorias e metacategorias possibilitou a construção do sistema de categorias. Para tanto, foram adotadas premissas que aproximam e distanciam um elemento do outro em um processo de comparação intra e intercategorias (Flores, 1994). O resultado está disposto na figura 1.

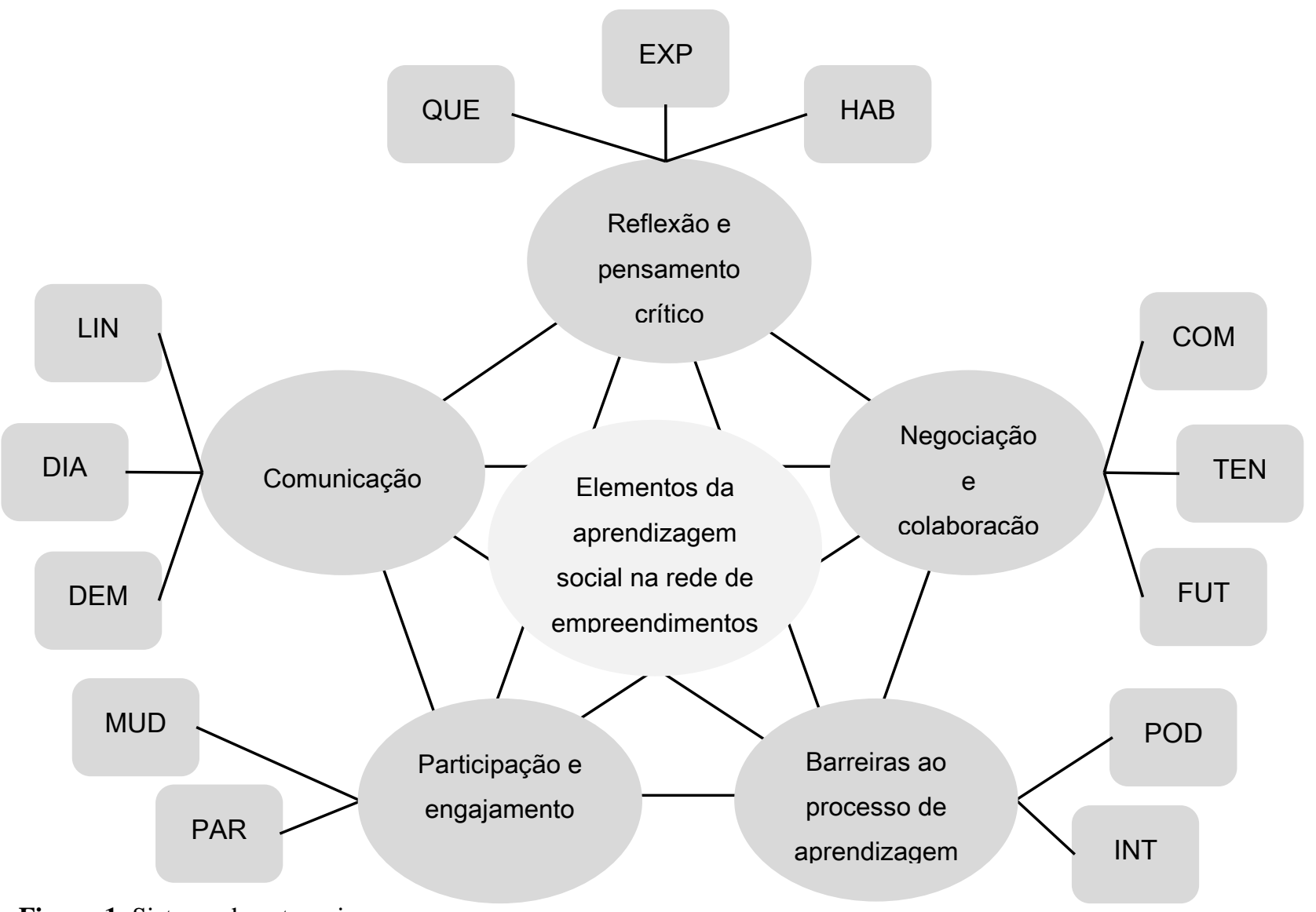

Figura 1. Sistema de categorias

Fonte: Elaborado pelos autores

\section{RESULTADOS DA PESQUISA}

O sistema de categorias apresentado na seção de procedimentos metodológicos (figura 1) foi utilizado como base para o exame dos elementos críticos que promovem a aprendizagem social nas redes de empreendimentos. Embora o desenho demonstre uma separação de categorias e metacategorias, a análise não necessariamente foi assim subdividida. Essa configuração é meramente didática, pois na realidade cotidiana se misturam. Os relatos provenientes das mulheres e as notas de campo das observações, aqui transformadas em textos, foram mesclados com a intenção de tornar a compreensão mais fluida. Deste modo, ao invés de 
analisar os elementos críticos individualmente (Questionamento - QUE; Diálogo - DIA; Hábitos - HAB), por exemplo, optou-se por agrupá-los, resultando naquilo que se denominou de enunciado.

O enunciado sintetiza a essência da ideia ou do comportamento observado e relatado a partir do agrupamento das categorias. No exemplo anterior, as três categorias foram condensadas numa sentença construída por meio dos dados coletados no campo: "A importância do questionamento estimulado pelo diálogo na criação de novos hábitos". Ao todo foram elaborados oito enunciados divididos em tópicos que, por sua vez, comparam os dados obtidos em campo (redes de empreendimentos), concernentes à dimensão organizacional da aprendizagem social, com os aspectos dos estudos da ASpS, discutidos no referencial teórico deste estudo (tabela 5).

Tabela 5.

Relação entre os elementos críticos da aprendizagem social em diferentes perspectivas.

\begin{tabular}{|c|c|c|}
\hline \multirow{2}{*}{ Enunciado } & \multicolumn{2}{|c|}{ Perspectiva da aprendizagem social } \\
\hline & Organizacional & Sustentabilidade \\
\hline $\begin{array}{l}\text { O compromisso com } \\
\text { os empreendimentos } \\
\text { mediante a busca } \\
\text { comum de um futuro } \\
\text { melhor e a } \\
\text { participação no grupo } \\
\text { (COM \& FUT \& } \\
\text { PAR). }\end{array}$ & $\begin{array}{l}\text { As empreendedoras que } \\
\text { compartilhavam visões de futuro } \\
\text { semelhantes mostraram-se mais } \\
\text { comprometidas. } \\
\text { A participação no grupo foi vista como } \\
\text { benéfica para a continuidade dos } \\
\text { empreendimentos, pois auxiliou o } \\
\text { processo de resolução de problemas e a } \\
\text { formação de um ambiente de trabalho } \\
\text { mais familiar. }\end{array}$ & $\begin{array}{l}\text { A visão de futuro busca resolver as diferenças de } \\
\text { expectativas dos diversos atores. Quando } \\
\text { alinhadas, estimulam o comprometimento dos } \\
\text { envolvidos. } \\
\text { Por seu caráter colaborativo, possibilita desafiar } \\
\text { os modelos mentais em voga em razão das } \\
\text { diferentes perspectivas dos indivíduos, além de } \\
\text { criar sinergia no trabalho. }\end{array}$ \\
\hline $\begin{array}{l}\text { A mudança de } \\
\text { comportamento } \\
\text { motivada pela } \\
\text { experiência diária } \\
\text { (MUD \& EXP). }\end{array}$ & $\begin{array}{l}\text { As mulheres aprenderam, na prática, } \\
\text { que a mudança de atitude era } \\
\text { importante para a manutenção dos } \\
\text { empreendimentos. }\end{array}$ & $\begin{array}{l}\text { A aprendizagem social está associada às ações e } \\
\text { mudanças oriundas da vivência diária. }\end{array}$ \\
\hline $\begin{array}{l}\text { A importância do } \\
\text { questionamento } \\
\text { estimulado pelo } \\
\text { diálogo na criação de } \\
\text { novos hábitos (QUE } \\
\text { \& DIA \& HAB). }\end{array}$ & $\begin{array}{l}\text { Os questionamentos das práticas } \\
\text { vigentes resultaram em mudanças de } \\
\text { hábitos dos empreendimentos, por } \\
\text { meio do diálogo entre as participantes. }\end{array}$ & $\begin{array}{l}\text { Situações de desconforto estimulam } \\
\text { questionamentos necessários ao confronto de } \\
\text { modelos atuais, desde que permeados pelo } \\
\text { diálogo entre os atores. }\end{array}$ \\
\hline $\begin{array}{l}\text { A experiência } \\
\text { advinda da } \\
\text { participação no dia a } \\
\text { dia (EXP \& PAR). }\end{array}$ & $\begin{array}{l}\text { A prática diária foi imprescindível para } \\
\text { o aprendizado das mulheres, } \\
\text { principalmente nos empreendimentos } \\
\text { que estimularam o método de tentativa } \\
\text { e erro. }\end{array}$ & $\begin{array}{l}\text { O compartilhamento de experiências em um } \\
\text { clima de colaboração entre os participantes } \\
\text { favorece o aprendizado, fruto de interações no } \\
\text { ambiente de grupo que remetem à ação e à } \\
\text { mudança. }\end{array}$ \\
\hline $\begin{array}{l}\text { O poder exercido por } \\
\text { um indivíduo limita a } \\
\text { participação e } \\
\text { experiência de outros } \\
\text { (POD \& PAR \& } \\
\text { EXP). }\end{array}$ & $\begin{array}{l}\text { A centralização de atividades nas mãos } \\
\text { de uma empreendedora impossibilitou } \\
\text { o aprendizado das outras colegas. }\end{array}$ & $\begin{array}{l}\text { A hierarquização é vista como um obstáculo para } \\
\text { o desafio de modelos mentais vigentes, uma vez } \\
\text { que limita a colaboração de múltiplos atores. }\end{array}$ \\
\hline $\begin{array}{l}\text { As situações de } \\
\text { conflitos e tensões são } \\
\text { resolvidas pelo } \\
\text { diálogo (TEN \& } \\
\text { DIA). }\end{array}$ & $\begin{array}{l}\text { O diálogo foi responsável pela } \\
\text { resolução de conflitos e o aprendizado } \\
\text { se deu na conversa entre os integrantes } \\
\text { do empreendimento. }\end{array}$ & $\begin{array}{l}\text { Os conflitos estão presentes em discussões que } \\
\text { envolvem diferentes atores e estimulam a troca de } \\
\text { experiências e ideias de terceiros que, até então, } \\
\text { nunca tinham sido abordadas. }\end{array}$ \\
\hline $\begin{array}{l}\text { Os diálogos são } \\
\text { proveitosos quando } \\
\text { possuem linguagem } \\
\text { transparente e } \\
\text { democrática (DIA \& } \\
\text { LIN \& DEM). }\end{array}$ & $\begin{array}{l}\text { Os diálogos possibilitaram o consenso } \\
\text { nos empreendimentos, principalmente } \\
\text { nos ambientes onde os participantes } \\
\text { promoveram a transparência e clareza } \\
\text { nas conversas. }\end{array}$ & $\begin{array}{l}\text { O aprender está ligado a vários processos de } \\
\text { comunicação, por isso a importância de ser } \\
\text { realizada abertamente, de forma transparente } \\
\text { entre os participantes e por intermédio do } \\
\text { diálogo. }\end{array}$ \\
\hline $\begin{array}{l}\text { Interações frágeis } \\
\text { entre os indivíduos }\end{array}$ & $\begin{array}{l}\text { As interações frágeis entre os } \\
\text { participantes interromperam o processo }\end{array}$ & $\begin{array}{l}\text { A comunicação aberta entre os envolvidos, } \\
\text { combinada com o aumento de confiança e formas }\end{array}$ \\
\hline
\end{tabular}


resultam em diálogos $\quad$ de reflexão-ação, demandando uma pouco construtivos ou intervenção do Educador Social do inexistentes (INT \& $\quad$ ICM para a resolução de problemas. mais igualitárias de participação, possibilita uma percepção reflexiva e definição de problemas por parte dos participantes.

Nota. Tabela elaborada pelos autores.

Os dados que corroboram tais associações e o contexto em que aparecem são aprofundados em cada enunciado, a seguir, a partir dos relatos das entrevistas e observações de campo.

\subsubsection{O compromisso com os empreendimentos mediante a busca comum de um futuro melhor e a participação no grupo (COM \& FUT \& PAR)}

O compromisso assume um papel importante na aprendizagem social, devido ao estímulo ao compartilhamento de experiências por parte dos envolvidos. Contudo, a discussão sobre a visão de futuro, ou seja, expectativas e ideais, precisam ser uniformes ou buscar um consenso, caso contrário, os que estiverem “desconectados" se afastarão (Dyball, Brown \& Keen, 2007; Tilbury, 2007).

O esforço para alcançar um futuro melhor por parte das mulheres participantes da rede de empreendimentos foi um fator determinante para o compromisso individual com o negócio e, portanto, com as colegas sócias. Os empreendimentos que possuíam como característica o comprometimento individual dos envolvidos tinham algo em comum, além da participação no grupo: a manutenção dos interesses do coletivo em detrimento do individual. Nestes ambientes, havia estímulos às discussões e tomadas de decisão em conjunto, tendo em vista a resolução de problemas.

Muito mais que o aumento da renda, outros fatores foram explicitados nas reflexões das empreendedoras entrevistadas quando questionadas sobre a principal motivação em participar e se comprometer com o Programa: o sonho de trabalhar no ramo da alimentação (E2) e a oportunidade de aprendizado e crescimento (E5).

E2 - De tudo isso que te falei, isso aqui é algo que eu sonhei. Porque eu sei que a gente aprende. Nesse 1 ano que eu tô aqui, aprendi muita coisa. De tudo isso que acontece, eu me sinto bem de vir aqui. Porque antigamente eu trabalhava em um lugar, em casa de família, e eu sempre falava pra minha mãe: "Eu não quero isso pra mim". Não que seja vergonha, mas era uma coisa que eu não queria. Eu queria algo que era trabalhar nessa área de gastronomia, de fazer uma faculdade, de fazer um curso.

E5 - Eu gosto de cozinhar, gosto de produzir, e aí eu sou louca a aprender a fazer bolo confeitado. Então, onde eu sei que tem, eu vou atrás. Aí eu achei que seria uma oportunidade de crescer assim, aprendendo a fazer doces e salgados. [...]. E aí eu vou ficar vendo as outras fazendo, vou ter curiosidade e em cima delas eu vou aprender.

No contexto da ASpS, a visão de futuro sustentável (FUT) associa os contextos socioambientais de acordo com as ambições individuais, buscando resolver as diferenças de expectativas dos diversos atores (Tilbury, 2007), que, quando alinhadas, fomentam o compromisso (COM) dos envolvidos à causa de um projeto. Ademais, a participação em rede social possibilita: (i) a quebra de hierarquias e confrontos aos modelos tradicionais de estruturas de poder; (ii) desafios dos modelos mentais em voga ao trazer pessoas e grupos com diferentes perspectivas e níveis; e (iii) criação de sinergia no trabalho para maximização das oportunidades envolvidas (Tilbury, 2007).

$\mathrm{Na}$ rede de empreendimentos, o comprometimento (COM) assumiu um papel essencial na aprendizagem e, por conseguinte, à busca de um futuro comum (FUT) pelas empreendedoras, relacionado diretamente à melhoria de qualidade de vida. A ausência de uma visão uniforme ocasionava problemas concernentes ao comprometimento e adesão ao grupo. Da mesma forma, a participação (PAR) no grupo foi vista como benéfica na continuidade dos empreendimentos, pois auxiliou no processo de resolução de problemas e na formação de um ambiente de trabalho mais colaborativo.

\subsubsection{A mudança de comportamento motivada pela experiência diária (MUD \& EXP)}

A proximidade no dia a dia da operação proporcionou uma mudança de postura (MUD) das empreendedoras, graças à maior participação (PAR) no negócio, embora ainda considerassem que estivessem assimilando novos conhecimentos, como parte de uma formação contínua. As empreendedoras aprenderam que a mudança de comportamento foi imprescindível para resolução dos problemas, necessária para salvaguardar o bom funcionamento do negócio. Os discursos enfatizaram a necessidade de 
entendimento dos diferentes pontos de vista, respeito à diversidade, clareza no apontamento do que precisa ser melhorado, controle emocional e o exercício da paciência.

\begin{abstract}
Entrevistador - E o que foi necessário aprender para que essa interação entre vocês [mulheres do empreendimento] desse certo?

E2 - Estou aprendendo a deixar o meu limite mais baixo, sabe? Às vezes engolir sapo pra gente vê aqui crescer. Tanto que agora vai passar [o carrinho solidário] em mais três andares. Vai crescer muito mais e, fora isso, não é só nervoso ou ignorância. Querendo ou não é algo que você tem que tá centrada, e quando você tá centrada o seu psicológico consegue movimentar muita coisa na sua cabeça com algo que antigamente você não tinha e agora você tem.
\end{abstract}

Ainda assim, era importante que a cultura de aprendizagem estivesse presente no grupo para consolidar o conhecimento, como visto na rede da Anchieta. Durante a entrevista de uma candidata a nova sócia, ouviu-se discursos de motivação para experimentar: "Aqui você aprende na prática" ou "Se o bolo não sair bom, não tem problema. Vai fazer até aprender". Além disso, demonstraram abertura para o novo, utilizando-se da prerrogativa de serem donas do próprio negócio: "Tente trazer um doce ou salgado, apresente para gente e vamos juntas! Aqui não tem chefe, tem liberdade, mas precisa de proatividade".

A reflexão por si só não é considerada sinônimo de aprendizagem social, mas sim uma etapa importante que precede as mudanças em diferentes níveis (Reed et al., 2010). No cenário das redes de empreendimentos, as transformações começaram individualmente nas empreendedoras, a partir da reflexão sobre a importância de manter a unidade do grupo, por meio da boa convivência. Em seguida, englobou o nível dos empreendimentos, graças às interações sociais entre as profissionais envolvidas na rotina do negócio, e responsáveis por estimular uma cultura de colaboração e aprendizado no negócio.

\title{
4.1.3 A importância do questionamento estimulado pelo diálogo na criação de novos hábitos (QUE \& DIA \& HAB)
}

As mudanças começaram individualmente, a partir da reflexão sobre a importância de manter, por meio da boa convivência, a unidade do grupo. Só então, a prática foi institucionalizada nos empreendimentos. No entanto, a mudança só se tornou um efeito prático do aprendizado quando precedida por questionamentos (QUE) de práticas vigentes, devidamente alicerçados pelo diálogo (DIA) entre as envolvidas.

A aprendizagem iniciou-se quando as mulheres se depararam com problemas, posteriormente resolvidos, por meio de diálogos e pensamentos reflexivos, criando novos hábitos (HÁB) aceitos pelos grupos. Na rede da Anchieta, por exemplo, o excesso de trabalho das empreendedoras era o maior problema. Elas trabalhavam 11 horas por dia, em média, quando o normal seriam 8 horas. A qualidade de vida das mulheres estava ameaçada, conforme relato.

Entrevistador - A gente falou de aprendizado. Quais seriam as maiores dificuldades neste trabalho?

E6 - A gente precisa realmente trabalhar 8 horas por dia. É a falta do nosso horário mesmo, de um horário para almoçar. A gente não tem e então come de pé em 5 minutos. Mas eu entendo que a gente não tem isso ainda porque a gente não tem espaço, você entende? Então, a partir do momento que a gente tiver espaço, uma bancada para você fazer produção, uma bancada para você fazer almoço, com certeza a gente vai ter mais qualidade de vida e trabalhar 8 horas por dia. Porque a gente entra às $07 \mathrm{~h}$ e sai às $18 \mathrm{~h}$ : 11 horas por dia sem parar. Você sabe que é sem parar. Eu como de pé, todo mundo come de pé aqui. Ninguém come sentado.

Inicialmente, pensava-se que o espaço limitado para produção de alimentos era a principal causa das horas extras trabalhadas. Entretanto, graças às sucessivas discussões foi possível chegar ao cerne do problema: a divisão de tarefas entre as empreendedoras. Uma delas chegou a comentar que, em certas ocasiões, bastavam cinco pessoas para deixar o espaço pronto às $07 \mathrm{~h} 30$, enquanto outras vezes, quando as nove estavam presentes, não conseguiam dar conta do trabalho. A visão do grupo até então, no que tange à divisão de atividades, era: todas fazendo o que puderem ao mesmo tempo.

Ao final das discussões, que perduraram por cinco semanas, novos hábitos foram implantados para diminuição da carga horária. Como resultado, cada uma das empreendedoras teve uma redução de 50 horas de trabalho por mês para que pudessem se dedicar à sua vida pessoal. Neste ínterim, já surgiram novas reflexões, o que demonstrou o caráter recursivo do questionamento: (i) por que não fazer um cardápio 
específico de produtos por dia da semana? (ii) o que pode ser mudado das $09 \mathrm{~h}$ às $12 \mathrm{~h}$ sobre produção de salgado para não misturar com a produção do almoço? (iii) já que vai ter o foco em almoço, não seria interessante terceirizar os lanches e doces para outros empreendimentos que fazem parte da rede?

A ASpS sugere um confronto dos modelos atualmente existentes, buscando mudanças profundas a partir do estímulo às pessoas para desafiarem as práticas existentes (Jacobi, 2008; Loeber et al., 2007; Tilbury, 2007). Embora o questionamento seja um elemento crítico essencial na ASpS, ele só acontece mediante o diálogo entre os envolvidos (Tilbury, 2007), fruto de uma situação de desconforto entre os atores, por não terem atingido os resultados esperados.

Do mesmo modo, os questionamentos sobre a forma de agir fizeram com que os empreendimentos mudassem os seus hábitos. A atividade coletiva das mulheres da rede combinou, de forma recursiva, questionamentos e hábitos, permeados pelo diálogo: hábitos interrompidos desencadearam questionamentos, que geraram novos hábitos (Lorino, 2013). O agir transformou permanentemente ação passada em hábitos, que se tornaram mediadores das novas ações.

\subsubsection{A experiência advinda da participação no dia a dia (EXP \& PAR)}

A proximidade das mulheres com a operação diária dos negócios foi um fator que contribuiu para o aprendizado das empreendedoras. A prática assumiu uma posição de destaque no desenvolvimento da aprendizagem. O relato da E6 destacou o aprendizado da colega graças à prática na elaboração de um prato, assim como de todo o grupo, por meio da experimentação de novas ideias.

Entrevistador - O que faz com que vocês aprendam aqui em todas as atividades?

E6 - A necessidade de aprendizado. Porque eu vou pra casa pensando no que eu vou fazer pro outro dia. Aí já vou pesquisar uma coisa nova. Vou pesquisar um prato novo. Elas [as colegas de empreendimento] também fazem a mesma coisa. Trazem ideias de casa: "Gente eu tenho uma ideia, vamos experimentar fazer?". Nesse experimentar, você tá aprendendo. E aí se a ideia cola, se é bem aceita pelo público, pronto! É mais um prato que entrou. Então assim, acho que está despertando isso das pessoas aqui. Elas veem que no dia seguinte, na segunda-feira seguinte, eu chego com uma coisa nova. Então isso elas também estão começando a fazer.

$\mathrm{Na}$ ASpS, a aprendizagem social está ligada ao processo de ação social, desencadeada também por uma "necessidade" em particular (Wildemeersch, 2007). O compartilhamento de experiências, dentro de um clima de colaboração entre os participantes, favorece o aprendizado por meio de interações no ambiente de grupo (Keen et al., 2005), desde que remeta à ação e à mudança (Reed et al., 2010).

Nas redes de empreendimentos, observou-se que a prática diária é imprescindível para o aprendizado, quando suportado pelo estímulo do grupo. Tal compreensão reitera as ideias de Elkjaer e Simpson (1996) ao tratarem da experiência não como algo individual e particular, mas como um processo contínuo de acontecimentos nos quais há uma objetividade no compartilhamento social que, por sua vez, entrelaça-se com a dimensão subjetiva individual. Contudo, se a prática era importante para vivenciar uma experiência e, assim, resultar em aprendizado, em contrapartida, o poder exercido por um indivíduo do empreendimento foi capaz de limitar a atuação das outras empreendedoras, dificultando o processo de aprendizagem.

\subsubsection{O poder exercido por um indivíduo limita a participação e experiência de outros (POD \& PAR \& EXP)}

As empreendedoras da Berrini vivenciaram um cenário de centralização extrema das atividades por parte de uma das sócias, a qual designava às outras somente a venda de produtos. Após a sua saída, as mulheres que permaneceram no grupo foram contundentes ao afirmar que, à época, se sentiam limitadas, em vista disso não praticavam e, por consequência, nada aprendiam. Na dúvida, todas se protegiam de uma possível represália, fazendo apenas aquilo que era pedido: vender. O contexto, neste caso, impedia que assumissem uma postura de donas do seu próprio negócio. O processo de transição das atividades, após a saída da empreendedora responsável pela centralização, ocorreu naturalmente, segundo elas, por meio da divisão de atividades durante uma reunião do grupo.

E2 - A gente não fazia nada. Tudo era ela [a colega que centralizava as atividades]. Ela cortava as frutas, montava o sanduíche. A gente só vinha aqui pra vender e passar o carrinho. Não era nada da gente aqui. A gente depois, com o tempo, depois de 2 meses, que aí a gente começou a montar. A gente teve que arrumar a cozinha pra montar sanduíche,

Revista de Gestão Social e Ambiental - RGSA, São Paulo, v. 11, n. 3, p. 02-20, set./dez. 2017. 
salada de fruta, montar os almoços. Porque tudo vinha pronto, sabe? “Ó, você vai ser só o vendedor. Estou te pagando tudo e você vai vender". Agora não, todas somos vendedoras, como também montamos tudo, salada pra almoço, tudo a gente monta. Agora é tudo nosso. Ninguém ajuda a gente em mais nada.

Na ASpS, a hierarquização é vista como um obstáculo para o desafio de modelos mentais vigentes, uma vez que limita a colaboração de atores distintos. Por essa razão, defende-se a importância das parcerias e redes como forma de dividir responsabilidades e compartilhar aprendizagem em diversas questões (Tilbury, 2007). O seu caráter colaborativo torna a aprendizagem social sinônimo de diálogo e participação (Jacobi, 2008), o que contribui para o aprimoramento e desenvolvimento de capacidades individuais (Wossen, Berger, Mequaninte \& Alamirew, 2013). No âmbito das redes, mais precisamente na Berrini, verificou-se o prejuízo em termos de aprendizado, pelo fato de haver uma estrutura hierárquica centralizada, mesmo que informal, em uma organização, na qual, teoricamente, todas as integrantes deveriam possuir os mesmos direitos e deveres.

\subsubsection{As situações de conflitos e tensões são resolvidas pelo diálogo (TEN \& DIA)}

O diálogo (DIA) assume papel crucial na aprendizagem social, tanto nas questões de sustentabilidade quanto nas organizacionais. A partir dele é possível buscar o entendimento entre as partes envolvidas nas situações de divergências. $\mathrm{O}$ empreendimento da Berrini, como mencionado, passou por uma reestruturação decorrente da saída de uma empreendedora responsável pela centralização de atividades. Esse contexto de tensão (TEN) referente à mudança de composição do grupo, só foi possível de ser resolvido mediante uma conversa de alinhamento e divisão de atividades.

E2 - Tanto que teve uma situação, na época de Copa [do Mundo], a gente tava nesse processo de mudança que a Fulana saiu e entrou a gente. A gente se reuniu [...] na casa de Ciclana e a gente resolveu tudo: quem ia comprar, quem ia fazer as compras, conseguimos o cartão, falamos diretamente com o contador.

$\mathrm{Na}$ Anchieta, graças à iniciativa de determinada empreendedora, uma situação de conflito foi resolvida a partir do momento em que todo o grupo participou da conversa, sem distinções. A pauta da discussão se referia a uma das colegas que estava sendo alvo, sem saber, de questionamentos sobre a qualidade do seu trabalho, relatada pelas empreendedoras: "Muita tarefa que deveria ser feita e você fazia algo sem importância naquele momento. Tem que haver prioridade. $\mathrm{O}$ grupo não está satisfeito com o seu serviço". Também abordaram a questão da pontualidade: "Precisa chegar no horário para preparar a comida". A mulher que recebeu as críticas ratificou a importância de "falar na frente, sem picuinha". Após todas explicitarem os desconfortos, o grupo consentiu que, a partir deste episódio, tudo passaria a ser dito sem rodeios no momento exato do fato ocorrido, ou durante as reuniões. No relato da E6, semanas após o episódio, confirmou-se que o diálogo ajudou a resolver este conflito.

Entrevistador - Eu lembro uma vez numa reunião que eu vim aqui, um problema de comunicação que ninguém falava, nem todo mundo comentava.

E6 - Mudou isso. Acabou aquele negócio de picuinha.

Entrevistador - Só porque vocês conversaram?

E6 - Isso! Tem que chegar e falar. Bem simples, nada como lidar com a verdade, apesar de doer. Mas a mentira mata, sabe? A verdade dói e passa, a mentira mata. Mata qualquer relação, qualquer tipo de confiança, qualquer coisa. Um dia a gente ainda derruba isso. Criou outro clima no grupo.

O conflito de interesse é reconhecido como um elemento importante que promove a ASpS (Henry, 2009). As interações estimulam a troca de experiências e ideias de terceiros que até então, dentro de determinado entendimento, nunca tinham sido abordadas (Loeber et al., 2007). Por isso, a importância das relações moldadas pela comunicação, deliberação e negociação (Rist et al., 2007). Nas redes de empreendimentos, o diálogo foi responsável por evitar e resolver conflitos. O aprendizado se deu nas conversas entre os integrantes dos negócios que, posteriormente, refletiram sobre a forma como estavam lidando umas com as outras. 


\subsubsection{Os diálogos são proveitosos quando possuem linguagem transparente e democrática (DIA \& LIN \& DEM)}

O papel do diálogo nas redes de empreendimentos era claro: evitar e resolver conflitos. O aprendizado se deu nas conversas entre os integrantes dos negócios que refletiram diretamente sobre a forma como lidavam umas com as outras. No entanto, os diálogos eram considerados benéficos quando democráticos (DEM) e com linguagem transparente (LIN), estimuladas por um contexto que promovia tal prática entre os atores envolvidos. Em suma, o diálogo foi visto como um dos fatores que facilitava o aprendizado das mulheres na rede de empreendimentos por meio da troca de experiências e reflexões.

Os diálogos construtivos na rede de empreendimentos surgiam em ambientes que estimularam tal prática. Na Anchieta, por exemplo, uma das empreendedoras encorajara a novata em expor a sua opinião quando necessário: "Todo mundo te ouve! Se concorda, tudo bem. Se não, não!”. Em compensação, a ausência do diálogo, do ponto de vista das mulheres, era um obstáculo à realização do trabalho, assim como a incapacidade de ouvir o outro durante as conversas.

Entrevistador - Você acha que nesse diálogo todo mundo é ouvido da mesma forma?

E2 - Não. Às vezes, não. Às vezes diferencia as palavras, muda as palavras. Acaba ficando até ruim. Se vai conversar, você coloca algo na conversa e geralmente as pessoas entendem de outra forma. Acaba isso causando discórdia. Mas nem todo mundo entende do jeito que a gente fala. Não só eu, mas as meninas também.

$\mathrm{Na}$ ASpS, o aprender está ligado (apoiado ou inibido) por vários processos de comunicação que ocorrem dentro e fora do sistema social (Wildemeersch, 2007), por isso a importância do diálogo aberto e transparente entre os participantes (Schusler, Decker \& Pfeffer, 2003). Quanto às redes, os diálogos incentivaram o consenso das empreendedoras, estimulado pelo contexto em que as participantes promoveram a transparência e clareza nas conversas. Consequentemente, a ausência de diálogo e a dificuldade de ouvir a parceira foram vistos pelas mulheres como obstáculos ao trabalho.

\subsubsection{Interações frágeis entre os indivíduos resultam em diálogos pouco construtivos ou inexistentes (INT \& DIA)}

As interações frágeis (INT) entre os indivíduos do grupo influenciaram a qualidade dos diálogos, impactando negativamente o processo de reflexão-ação. Diversas situações relatadas nas entrevistas, ou observadas durante as reuniões da rede, corroboram com o prejuízo da qualidade dos diálogos fruto de problemas nas interações. As discussões sobre a baixa qualidade dos produtos fornecidos e os atrasos na entrega, por exemplo, deveriam ser de simples resolução, acompanhado por um processo de comunicação, na medida em que os problemas fossem identificados. No entanto, os diálogos ocorriam apenas por causa da facilitação do Educador Social, caso contrário, nem chegariam a ser tratados, haja vista as frequentes tentativas de diálogo sem sucesso entre os empreendimentos envolvidos.

E1 - Então a gente nunca teve problema com nenhum deles [fornecedores do empreendimento], só com ela [a fornecedora em questão]. É chato. Por isso que toda sextafeira é aquilo. Porque ela nunca admite estar errada. E parece que só ela entende de tudo. E isso é estressante. Como te falei, se fosse uma pessoa estourada, eu brigaria com ela toda semana. Mas eu prefiro ouvir, respirar, ficar focada e perguntar só o necessário. E não entrar na provocação. Porque se eu entrar vai ter briga. Tendo briga a gente não consegue resolver os problemas que têm que ser resolvidos, porque é o único dia da semana onde você tem que tirar suas dúvidas. Tirar dúvidas e resolver tudo que tem que resolver.

A comunicação aberta entre os envolvidos, combinada com o aumento de confiança e formas mais igualitárias de participação, possibilita uma percepção reflexiva e definição de problemas por parte dos participantes (Rist et al., 2007). A ação comunicativa, no contexto da ASpS, é baseada na busca de entendimentos compartilhados com base na validação subjetiva, pressupondo dar voz aos participantes ao mesmo tempo em que desenvolve a capacidade de ouvi-los (D'Angelo \& Brustein, 2014). Do mesmo modo, as interações frágeis nos empreendimentos interromperam o processo de reflexão-ação, uma vez que os problemas apenas puderam ser resolvidos mediante a facilitação dos Educadores Sociais do ICM.

Os resultados obtidos no campo ratificam as semelhanças entre os elementos críticos que promoveram a aprendizagem social nas perspectivas da ASpS e das organizações, justificados na presença de componentes estruturais do Programa Mulher Empreendedora que impulsionam a aprendizagem. $\mathrm{O}$ tópico seguinte trata de explicá-los e relacioná-los. 


\section{ANÁLISE E DISCUSSÃO DOS RESULTADOS}

Os doze anos de experiência do ICM trouxe à tona mudanças no processo de assessoria de empreendimentos populares. A principal delas diz respeito à estruturação da rede de empreendimentos de alimentação. Entre 2011 e 2013, em São Paulo especificamente, os negócios deste ramo de atividade apresentaram aumento de $181 \%$ na sua renda, enquanto nas outras áreas (artesanato, costura, dentre outros) demonstraram crescimento de 131\% (Instituto Consulado da Mulher, 2014).

Os números evidenciam que os empreendimentos pertencentes à rede de alimentação obtiveram maiores rendimentos do que outros assessorados isoladamente. Cinco fatores explicam esse resultado. Em primeiro lugar, a criação de uma cadeia de produção e venda baseada na transparência entre os empreendimentos. A partir de um processo de precificação dos produtos e definição da margem de lucro, ambos assessorados pelo ICM, os negócios participantes da rede são estimulados a transacionar entre si. Dessa forma, eles podem comercializar mercadorias com valores acessíveis e condizentes com as normas de vigilância sanitária.

O segundo e terceiro fatores tratam, respectivamente, da formatação da rede de empreendimentos e, por conseguinte, da possibilidade de troca de experiências e ajuda mútua. As reuniões semanais propiciam momentos de reflexão das empreendedoras para solucionar problemas, além de serem consideradas estimulantes para o diálogo e planejamento das ações. Esses encontros são estruturados a partir de duas pautas complementares: uma sugerida pelos empreendimentos, responsáveis por propor assuntos que, na visão das suas representantes, precisam ser rapidamente resolvidos; a outra pauta, proposta pelo Educador Social, compreende demandas do Programa, além de outros aspectos institucionais que impactam no funcionamento da respectiva rede.

O quarto fator se refere à função do Educador Social no encaminhamento das reflexões e na facilitação dos processos de aprendizagem dos integrantes do empreendimento. No seu ponto de vista, o protagonista do processo de geração de renda são as mulheres participantes do projeto. Pelo aprendizado e construção de novos saberes, esse público tem condições de provocar mudanças em sua vida, na família e na comunidade. Por esse motivo, o Educador atua com maturidade em relação aos conflitos, procurando entender suas origens, em alguns casos, relacionados à divergência de opiniões, em outros, como consequência da necessidade de melhoria organizacional, definição de funções, divisão de tarefas e estabelecimento de regras.

Assim, o processo de reflexão-ação, o quinto fator, importante à aprendizagem social, também é estimulado por este profissional. Graças aos seus questionamentos é possível provocar as necessidades de mudança por parte das empreendedoras.

Em resumo, a cadeia de suprimentos auxilia a consolidação da rede de empreendimentos. Esta, favorece a troca de experiência entre os negócios participantes, facilitada pelo Educador Social. Este profissional, por sua vez, estimula o processo de reflexão-ação das empreendedoras que, por conseguinte, fortalece a cadeia de suprimentos da rede, devido à conexão criada entre os empreendimentos produtores e vendedores da rede de alimentação.

\section{CONSIDERAÇÕES FINAIS}

A literatura de aprendizagem social se concentra em discussões ambientais, mais precisamente, em como envolver múltiplos atores com diferentes visões e objetivos na gestão de recursos naturais (Maarleveld \& Dangbégnon, 1999; Pahl-Wostl et al., 2007). Diante disso, essa pesquisa buscou, como contribuição à literatura de ASpS, discutir o processo de aprendizagem social à luz da sustentabilidade social, em um projeto de combate à pobreza.

Três fatores-chave do Programa Mulher Empreendedora foram os responsáveis por estimular a aprendizagem social entre as participantes: (a) a possibilidade de troca de experiências, incentivada pelo formato da rede de empreendimentos; (b) o estímulo à qualidade de um diálogo mais aberto e democrático; e (c) a necessidade de um mediador, o Educador Social, encarregado pelo processo de facilitação das discussões e reflexões.

Os fatores-chave do Programa, por sua vez, criaram condições para a existência de cinco elementos críticos que influenciaram, em maior ou menor grau, o nível de aprendizagem social das empreendedoras: (1) Reflexão e pensamento crítico: frente a um problema ou situação incerta; (2) Negociação e colaboração: a partir do compromisso individual das mulheres, visão de futuro e superação dos conflitos e tensões; (3) Barreiras ao processo de aprendizagem: os obstáculos à aprendizagem derivados da centralização de determinadas empreendedoras e das interações frágeis entre os membros do grupo; (4) Participação e 
engajamento: o papel da participação das mulheres no dia a dia dos empreendimentos, por meio das interações entre colegas; (5) Comunicação: a importância do diálogo claro, transparente e democrático para o processo de aprendizagem.

Adicionalmente, por meio da articulação teórica demonstrada no quadro analítico da aprendizagem social e dos achados em campo, foi possível identificar pontos em comum entre a aprendizagem social no ambiente organizacional e para sustentabilidade, e compreender, na prática, como estes conceitos teóricos puderam ser evidenciados a partir do caso analisado.

As questões de cunho pessoal influenciam qualquer organização, porém nos empreendimentos pesquisados, assumiram um papel significativo. O que seria um problema de fácil resolução em uma grande organização tomava grandes proporções na rede de empreendimentos, em parte explicado pela conjuntura sociocultural das mulheres participantes.

Neste contexto, atribuiu-se ao Educador Social uma importante função de estimular o questionamento e diálogo por parte das mulheres. Provavelmente, sem a presença deste profissional, algumas discussões permaneceriam na esfera do problema. Contudo, longe de assumir um posicionamento de executor do processo de mudança dos empreendimentos da rede, o Educador apenas facilitava as discussões. Todas as soluções adotadas pelas empreendedoras em seus respectivos negócios partiram delas até chegar a um consenso. Essas discussões só foram possíveis em razão do formato de rede, pois diferentes representantes dos empreendimentos participavam dos diálogos, contribuíam para as reflexões e compartilhavam experiências reciprocamente.

É importante salientar que o Programa Mulher Empreendedora tem como objetivo estimular a independência das participantes a médio prazo, portanto, a saída de algumas delas do Programa será, mais cedo ou mais tarde, inevitável. No entanto, para evitar problemas de aprendizado das empreendedoras remanescentes, fica uma reflexão: o que pode ser feito para que o processo de aprendizagem na rede de empreendimentos não seja prejudicado com a saída de mulheres mais experientes?

Uma das possibilidades, sob a ótica da aprendizagem social, é estimular a maior interação entre os empreendimentos. Com o intuito de promover um maior aprendizado das participantes, seria interessante criar momentos de troca de experiência entre todos os empreendimentos da rede União dos Sabores Solidários (USS). É bem verdade que em muitos casos o Educador Social atua como ponte dessas experiências, mas os resultados podem gerar mais impacto se as interações também forem realizadas diretamente entre as empreendedoras novatas e experientes da rede.

Além disso, discussões sobre sustentabilidade neste projeto também devem contemplar a dimensão ambiental. Mesmo que ela esteja presente na metodologia do ICM, é preciso incorporá-la na prática cotidiana dos empreendimentos assessorados. A atenção somente aos fatores sociais é insuficiente, mesmo que este seja o objetivo primário da ação empresarial. E mesmo o debate teórico sobre ASpS tem de avançar nesta direção.

O Programa apresenta uma contradição. As mulheres participantes tiveram melhoras nas suas condições de vida, uma vez que deixaram de realizar trabalhos domésticos para serem sócias de seu próprio negócio. Em contrapartida, o excesso de trabalho nos empreendimentos afetava a qualidade de vida. A busca de uma sustentabilidade social reflete no balanceamento entre essas duas demandas: financeira e pessoal.

Os resultados positivos do Programa Mulher Empreendedora trazem implicações práticas para gestores que desejam criar projetos similares de desenvolvimento social por meio do combate à pobreza. Em razão de características específicas do público envolvido, como o nível de formação, por exemplo, é preciso que o aprendizado seja estimulado via experiência prática e com momentos de trocas de experiências, se possível, com um moderador, capaz de endereçar as discussões. Quanto à educação formal e tradicional, por meio de treinamentos, pode ser utilizada como fonte complementar e secundária de aprendizagem.

Em se tratando das limitações do estudo, é preciso ressaltar que a pesquisa foi desenhada a partir de um estudo de caso único. Por causa disso, os resultados apresentados devem ser compreendidos como experiências, na sua singularidade e no seu contexto. Pelo fato de o trabalho ter sido restrito à visão das mulheres empreendedoras, não foi possível entender o aprendizado que a empresa Consul obteve por meio do seu papel de mantenedora do Programa e como o transporta para seu ambiente organizacional. Tal discussão poderia trazer novas ideias sobre aprendizagem social em projetos de desenvolvimento social mantidos por empresas.

Cabe ainda sugerir uma agenda futura de pesquisa que aborde temas essenciais para a viabilização deste tipo de projeto em outras entidades. A primeira delas, sobre os elementos críticos que promovem a aprendizagem social: eles permaneceriam em um contexto diferente do pesquisado, por exemplo, fora do estado de São Paulo? A segunda: o sucesso do Programa continuaria se não houvesse o incentivo de uma 
grande empresa? A terceira: os resultados da pesquisa seriam os mesmos em um cenário de participação masculina?

Espera-se que a análise aqui empreendida possa ter trazido elementos teóricos e empíricos que contribuam para que novas investigações avancem na busca de respostas a estas e outras questões que envolvam iniciativas, tais como o combate à pobreza na ação empresarial e a construção de processos efetivos de Aprendizagem Social para Sustentabilidade.

\section{REFERÊNCIAS}

Boström, M. (2012). A missing pillar? Challenges in theorizing and practicing social sustainability: introduction to the special issue." Sustainability: Science, Practice, \& Policy 8(1).

Brandi, U., \& Elkjaer, B. (2006). Organizational dynamics: practice in the continuing transaction between structure and process. In: The second organization studies summer workshop on're-turn to practice: understanding organization as it happens.

Brandi, U., \& Elkjaer, B. (2013). Organizational learning: knowing in organizing. In: In M. Kelemen, \& N. Rumens (Ed.). American pragmatism and organization. Farnham, Surrey: Ashgate.

D’Angelo, M. J., \& Brunstein, J. (2014). Social learning for sustainability: supporting sustainable business in Brazil regarding multiple social actors, relationships and interests. International Journal of Sustainable Development \& World Ecology, 21(3), 273-289.

Dempsey, N., Bramley, G., Power, S., \& Brown, C. (2011). The social dimension of sustainable development: defining urban social sustainability. Sustainable Development, 19(5), 289-300.

Dlouhá, J., Barton, A., Janoušková, S., \& Dlouhý, J. (2013). Social learning indicators in sustainabilityoriented regional learning networks. Journal of Cleaner Production, 49, 64-73.

Dyball, R., Brown, V., \& Keen, M. (2007). Towards sustainability: five strands of social learning. In: Wals, A. E. J. (Ed). Social learning: towards a sustainable world. Wageningen: Wageningen Academic Publishers.

Edmondson, A. (1999). Psychological safety and learning behavior in work teams. Administrative Science Quarterly, 44(2), 350-383.

Edmondson, A. C. (2002). The local and variegated nature of learning in organizations: A group-level perspective. Organization Science, 13(2), 128-146.

Eizenberg, E., \& Jabareen, Y. (2017). Social sustainability: a new conceptual framework. Sustainability, 9(1), 68.

Elkjaer, B. (2004). Organizational learning: the 'third way'. Management Learning, 35(4), 419-434.

Elkjaer, B., \& Simpson, B. (2006). Towards a pragmatic theory of creative practice. In: Second organization studies summer workshop return to practice: understanding organization as it happens, Mykonos, Greece, June.

Fernandez-Gimenez, M., Ballard, H., \& Sturtevant, V. (2008). Adaptive management and social learning in collaborative and community-based monitoring: a study of five community-based forestry organizations in the western USA. Ecology and Society, 13(2).

Flores, J. G. (1994). Análisis de datos cualitativos: aplicaciones a la investigación educativa. Promociones y Publicaciones Universitarias, PPU.

Garmendia, E., \& Stagl, S. (2010). Public participation for sustainability and social learning: Concepts and lessons from three case studies in Europe. Ecological economics, 69(8), 1712-1722.

Hahn, R. (2009). The ethical rational of business for the poor-integrating the concepts bottom of the pyramid, sustainable development, and corporate citizenship. Journal of Business Ethics, 84(3), 313-324.

Henry, A. D. (2009). The challenge of learning for sustainability: a prolegomenon to theory. Human Ecology Review, 16(2), 131-140. 
Huysman, M., \& Elkjaer, B. (2006). Organizations as arenas of social worlds; towards an alternative perspective on organizational learning? In: International Conference on Organizational Learning, Knowledge and Capabilities, Coventry, England.

Instituto Consulado da Mulher. (2014). Resultados. Recuperado em 25 de novembro, 2014, de http://consuladodamulher.org.br/resultados/

Jacobi, P. R. (2008). Governança da água e aprendizagem social no Brasil. Sociedad Hoy, (15), 25-44.

Keen, M., Brown, V., \& Dyball, R. (2005). Social learning: a new approach to environmental management. In: Keen, M., Brown, V., Dyball, R. Social learning in environmental management: building a sustainable future. London: UK, Earthscan,

Lélé, S. M. (1991). Sustainable development: a critical review. World development, 19(6), 607-621.

Loeber, A. L., Mierlo, B., Grin, J. \& Leeuwis, C. (2007). The practical value of theory: conceptualizing learning in the pursuit of a sustainable development. In: Wals, A. E. J. Social learning: towards a sustainable world. Wageningen: Wageningen Academic Publishers.

Lorino, P. (2013). Transaction and transformation: a pragmatist perspective on learning as transforming action and transacting forms. In International Conference on Organizational Learning, Knowledge and Capabilities, The George Washington University, Washington DC, USA.

Maarleveld, M., \& Dabgbégnon, C. (1999). Managing natural resources: a social learning perspective. Agriculture and human values, 16(3), 267-280.

Pahl-Wostl, C., Sendzimir, J., Jeffrey, P., Aerts, J., Berkamp, G., \& Cross, K. (2007). Managing change toward adaptive water management through social learning. Ecology and Society, 12(2).

Reed, M., Evely, A. C., Cundill, G., Fazey, I. R. A., Glass, J., Laing, A., Newig, J., Parrish, B., Prell, C., Raymond C., \& Stringer, L. (2010). What is social learning? Ecology and Society, 12(2).

Rist, S., Chidambaranathan, M., Escobar, C., Wiesmann, U., \& Zimmermann, A. (2007). Moving from sustainable management to sustainable governance of natural resources: the role of social learning processes in rural India, Bolivia and Mali. Journal of Rural Studies, 23(1), 23-37.

Shipton, H., \& DeFellipi, R. (2003). Psychological perspectives underlying theories of organizational learning. In: Easterby-smith, M., \& Lyles, M. A. (Ed.) The Blackwell handbook of organizational learning and knowledge management, 19-35. Oxford, UK: Blackwell Publishing, 19-35.

Schusler, T.M, Decker, D. J., \& Pfeffer, M. J. (2003). Social learning of collaborative natural resource management. Society and Natural Resources, 15, 309-326.

Strauss, A. L. (1993). Continual permutations of action. AldineTransaction. New York: Aldine de Gruyter.

Tilbury, D. (2007). Learning based change for sustainability: perspectives and pathways. In:

Tinker, I. (2000). Alleviating poverty: investing in women's work. Journal of the American planning association, 66(3), 229-242.

Vallance, S., Perkins, H. C., \& Dixon, J. E. (2011). What is social sustainability? A clarification of concepts. Geoforum, 42(3), 342-348.

Vifell, Å. C., \& Soneryd, L. (2012). Organizing matters: how 'the social dimension'gets lost in sustainability projects. Sustainable Development, 20(1), 18-27.

Wals, A. E., \& Rodela, R. (2014). Social learning towards sustainability: Problematic, perspectives and promise. NJAS-Wageningen Journal of Life Sciences, 69, 1-3.

Wildemeersh, D. (2007). Social learning revisited: lessons learned from North and South. In:.

Wossen, T., Berger, T., Mequaninte, T., \& Alamirew, B. (2013). Social network effects on the adoption of sustainable natural resource management practices in Ethiopia. International Journal of Sustainable Development \& World Ecology, 20(6), 477-483. 
Data da submissão: 11/04/2017

Data de aceite: $31 / 10 / 2017$

Revista de Gestão Social e Ambiental - RGSA, São Paulo, v. 11, n. 3, p. 02-20, set./dez. 2017. 